\title{
Giant Cell Tumour of the Skull Base Treated with Surgery, Stereotactic Radiosurgery and Denosumab: Case Report and Review of Literature
}

\author{
Jorge H. Guajardo¹, Cuauhtemoc de la Peña², Maria F. Gonzalez ${ }^{*}$, Cesar Gonzalez4, Carlos Cuilty ${ }^{5}$, \\ Horacio Decanini6
}

\footnotetext{
${ }^{1}$ Departments of Neurosurgery, Neuro-Oncology Unit, Hospital de Alta Especialidad Chistrus Muguerza, Monterrey, Nuevo León Mexico

${ }^{2}$ Radiosurgery, Neuro-Oncology Unit, Hospital de Alta Especialidad Chistrus Muguerza, Monterrey, Nuevo León Mexico ${ }^{3}$ Neuro-Oncology, Neuro-Oncology Unit, Hospital de Alta Especialidad Chistrus Muguerza, Monterrey, Nuevo León Mexico ${ }^{4}$ Oncology, Neuro-Oncology Unit, Hospital de Alta Especialidad Chistrus Muguerza, Monterrey, Nuevo León Mexico ${ }^{5}$ Otolaryngology, Neuro-Oncology Unit, Hospital de Alta Especialidad Chistrus Muguerza, Monterrey, Nuevo León Mexico ${ }^{6}$ Pathology, Neuro-Oncology Unit, Hospital de Alta Especialidad Chistrus Muguerza, Monterrey, Nuevo León Mexico Email: ${ }^{\star}$ gonzamafe@hotmail.com
}

How to cite this paper: Guajardo, J.H., de la Peña, C., Gonzalez, M.F., Gonzalez, C., Cuilty, C. and Decanini, H. (2017) Giant Cell Tumour of the Skull Base Treated with Surgery, Stereotactic Radiosurgery and Denosumab: Case Report and Review of Literature. Open Access Library Journal, 4: e3571.

https://doi.org/10.4236/oalib.1103571

Received: March 29, 2017

Accepted: May 13, 2017

Published: May 16, 2017

Copyright $\odot 2017$ by authors and Open Access Library Inc.

This work is licensed under the Creative Commons Attribution International License (CC BY 4.0).

http://creativecommons.org/licenses/by/4.0/

\begin{abstract}
Abstrct
Giant cell tumours (GCT) of the skull base account for approximately $1 \%$ of all GTC of the bone. Despite being considered as a benign neoplasm, they are locally aggressive with high recurrence rates after incomplete surgery. Due to the small number of cases reported in skull base, standardized treatment remains unclear. Even with new surgical techniques, a complete resection in skull base tumours is not always possible without functional compromise. Therefore, adjuvant therapy is essential to enhance local control and quality of life. We described a case treated successfully with primary surgery followed by Cyberknife stereotactic radiosurgery (SRS) and denosumab with a 48-month follow-up. To the best of our knowledge, the usage of combined therapy, SRS and denosumab, in skull base GCT has not been previously described.
\end{abstract}

\section{Subject Areas}

Neuroscience

\section{Keywords}

Giant Cell Tumour, Skull Base, Stereotactic Radiosurgery, Denosumab 


\section{Introduction}

Giant cell tumour (GCTs) of the bone are defined as a benign but locally aggressive primary neoplasm, representing approximately $5 \%$ of all skeletal tumors [1], which usually occur in the epiphyses of the long bones, particularly the distal femur, proximal tibia and distal radius. GCT involving the skull account for less than $1 \%$ of all GCT reported, commonly observed in the sphenoid or temporal bone [2]. Due to the small number of cases reported in this location, standardized treatment remains unclear [3] [4]. Surgery is considered a priority to prevent local recurrence; however, this anatomical location not always allows performing a complete resection of the tumour [5]. Adjuvant therapy has changed over the past years, mainly with the use of modern radiotherapy techniques and the discovery of a specific monoclonal antibody improving quality of life and survival in these patients. We report a case of GCT of the clivus and petrous bone, an extremely rare entity, treated with primary surgery followed by stereotactic radiosurgery and denosumab.

\section{Case Report}

\section{History and Examination}

A 34-year-old male with a three-month history of progressive right-sided hearing loss without any medical treatment, in June 2012, developed secondary dizziness, tinnitus and right facial palsy. His medical history was otherwise noncontributory and had no prior surgeries. Physical examination revealed right peripheral facial nerve palsy (CN VII) and deficit of the right vestibulocochlear nerve (CN VIII). No abnormalities in the trigeminal (CN V) and abducens (CN IV) nerves were seen. Audiogram revealed moderate mixed hearing loss on the right. Magnetic resonance imaging (MRI) of the brain showed an expansive, radiolucent, lytic mass with irregular shape involving the petrous bone, clivus and sphenoid body (Figure 1).

\section{Treatment description}
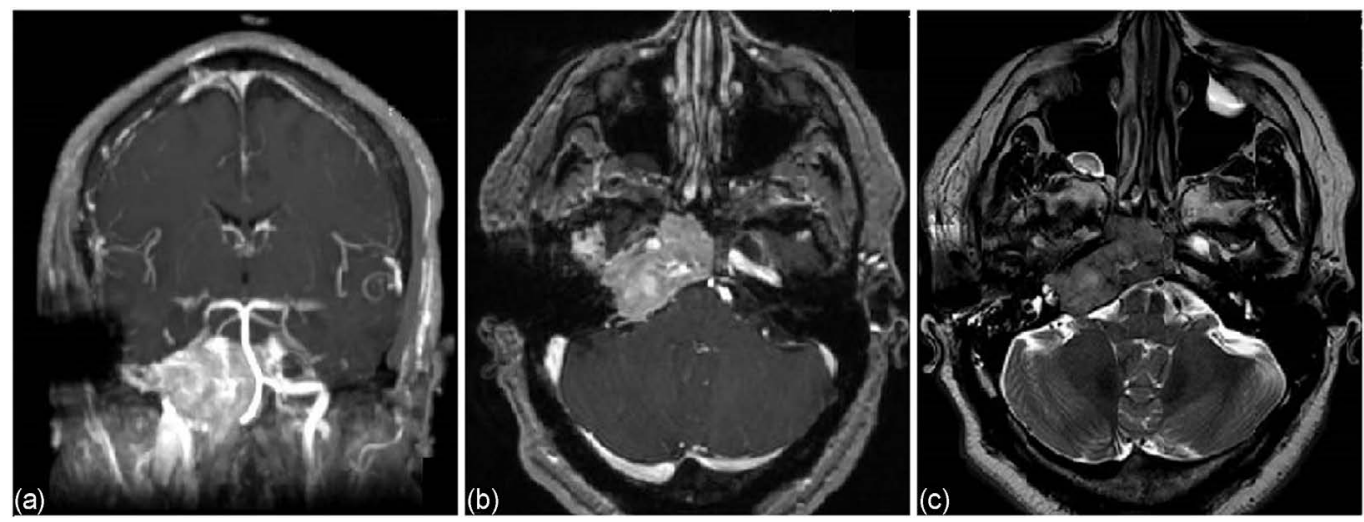

Figure 1. Initial MRI of giant cell tumour. Coronal maximum intensity projection (MIP) with contrast revealing an irregular expansive tumour with heterogeneous enhancement (a). Axial T1 with contrast (b) and T2 (c) presented an irregular tumor from the right petrous bone and clivus extending to the sphenoid body. 
The patient underwent a two-stage surgery, first a right temporal craniotomy and osteotomy of the zygomatic arch with a partial resection of the tumor including the anterior wall of the petrous bone, followed by endoscopic transnasal trans sphenoidal resection. A slightly hard and poorly vascularized mass was partially resected. The patient's postoperative course was uneventfully. Histopathology revealed a tumour composed of multinucleated giant cells in a proliferative spindle cell stroma. Stromal cell showed occasional mitotic figures with areas of osteoid production and hemorrhage. Immunostains for CD68 and Vimentin were positive in the multinucleated giant cells and stroma. Features that may suggest an aggressive lesion were not identified. The histopathology diagnosis was giant cell tumour (Figure 2).

To reduce local recurrence due to subtotal resection, he received adjuvant stereotactic radiosurgery (SRS) using the CyberKnife ${ }^{\varpi}$ system with a safety margin (clinical treatment volume CTV $20.6 \mathrm{cc}$ ) and a total dose of $20.1 \mathrm{~Gy}$ in 3 fractions, followed by subcutaneous injections of $120 \mathrm{mg}$ of denosumab administered monthly for the first year, then every 3 months during the second year and every 6 months from the third year to the current date. He also received daily supplements of calcium $600 \mathrm{mg}$ and vitamin D $400 \mathrm{IU}$.

\section{Follow-up}

Follow-up has been performed for 48 months with both clinical and imaging evaluation. After radiosurgery presented Radiation Therapy Oncology Group (RTOG) toxicity criteria grade 1 , due to tiredness but fully functional status, no late toxicity was observed during the follow up. The patient has not submitted any side effects of the drug and clinically continues with right-sided hearing loss
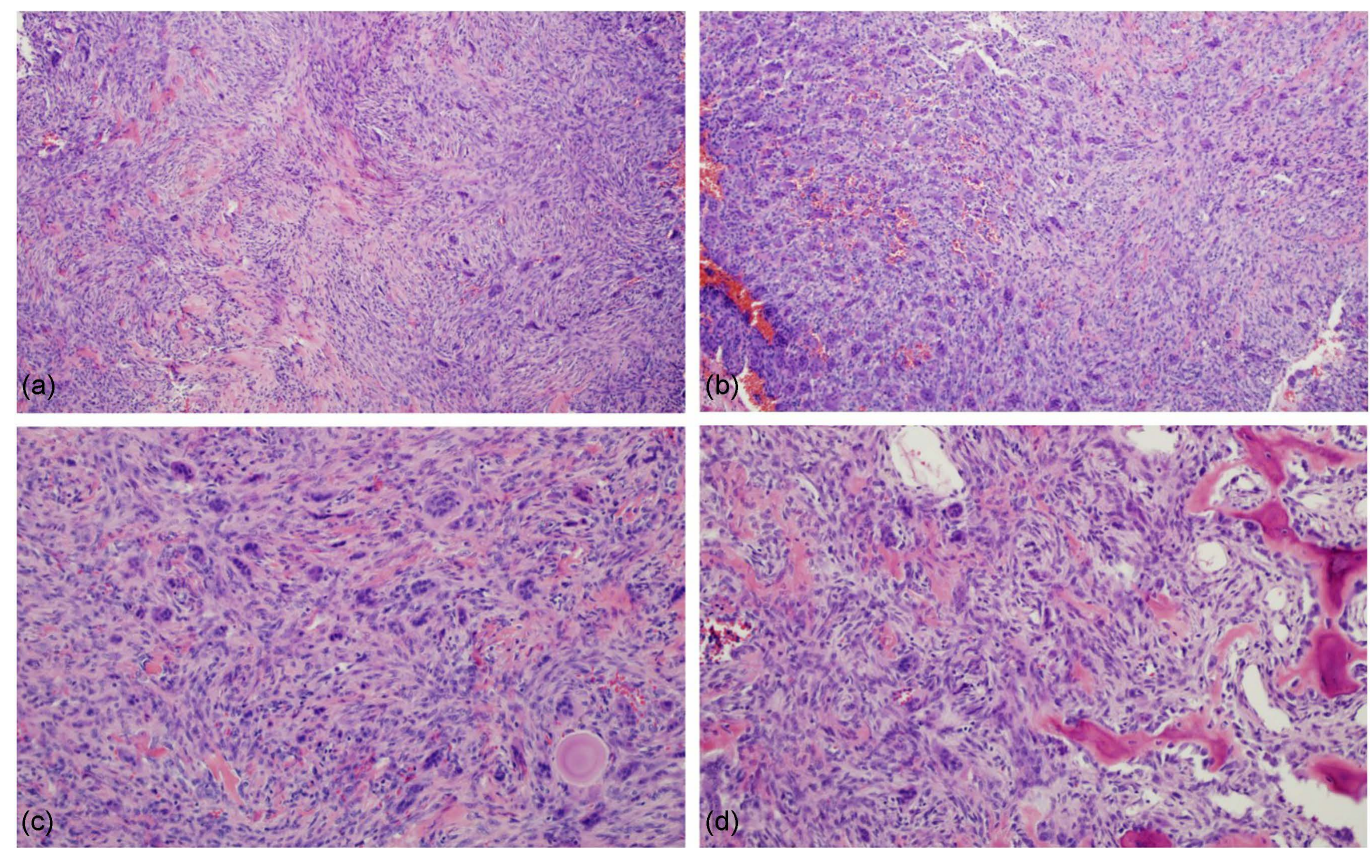

Figure 2. ((a), (b)) Histopathological findings showing multinucleated giant cells dispersed in a proliferation of spindled cell stroma (hematoxylin and eosin stain, magnification $\times 100)$. ((c), (d)) Some mitotic figures in mononuclear stromal cells were observed with areas of osteoid production (hematoxylin and eosin stain, magnification $\times 200$ ). 
but the facial palsy disappeared. MRI examination demonstrated a progressive regression of the tumour volume throughout the years (Figure 3). A tumor response diagram was performed, demonstrating a $65 \%$ tumor volume reduction compared to the post operative image and $71 \%$ reduction compared to the initial MRI (Figure 4).
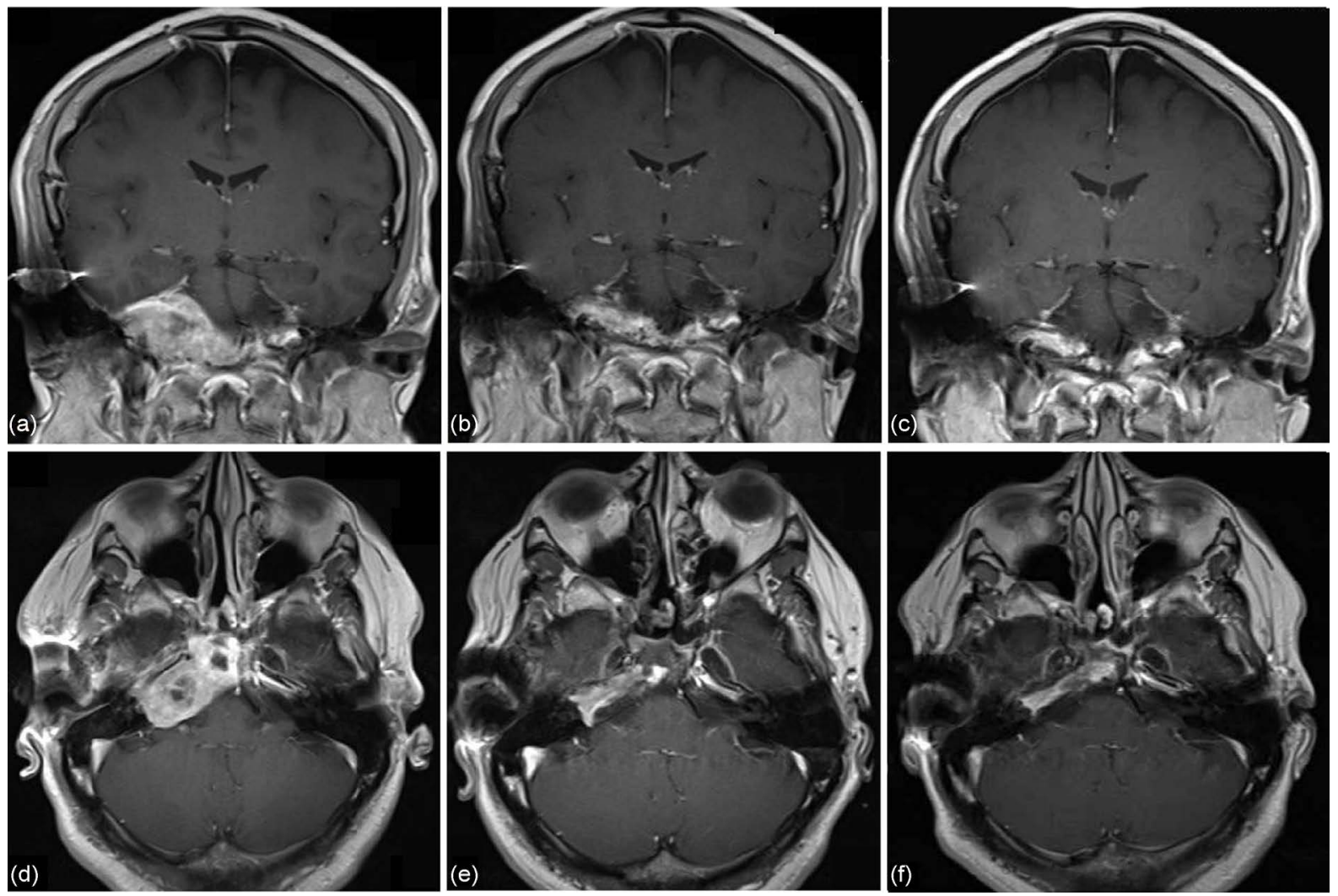

Figure 3. Radiological response of giant cell tumour of the skull base. Postoperative coronal and axial T1 magnetic resonance imaging $((\mathrm{a}),(\mathrm{d}))$ showing a residual tumor with zones of poor gadolinium enhancement. Followed by tumor regression observed twenty-four ((b), (e)) and forty-eight ((c), (f)) months after stereotactic radiosurgery and denosumab.

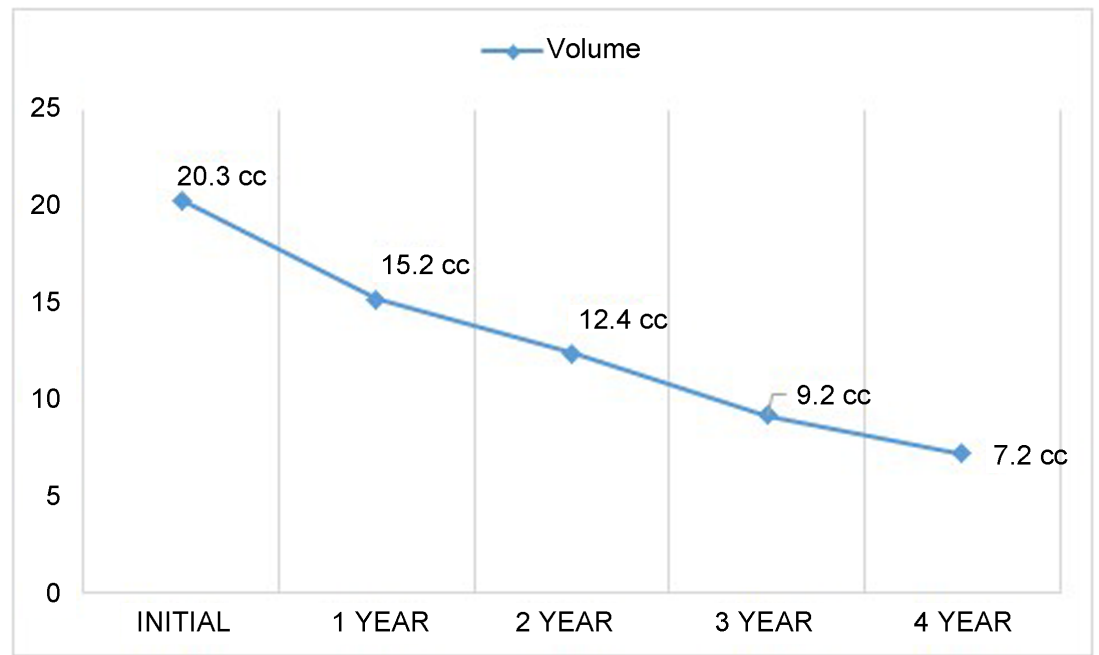

Figure 4. Tumor volume response diagram throughout the years. Initial volume described as the postoperative volume. 


\section{Discussion}

GCT are a primary bone tumor generally considered histologically benign, but locally aggressive, which typically occur in the epiphyses of long bones, rarely seen in the cranium. Skull base involvement is unique and only described in case reports [3] [6]. Uslu et al. reported a total of 115 cases available in literature of GCT of the cranium, most of them observed in the sphenoid and temporal bones [6]. We report a rare case of GCT affecting the petrous bone, clivus and sphenoid body.

The age of presentation is usually between 20 and 40 years with the predominance in females and Asian population [7]. The clinical symptoms vary widely depending on tumor location. Hearing loss, headache, tinnitus and dysfunction of the cranial nerves are the usual modes of presentation in skull base involvement [8]. In our patient, despite the location of the tumor, the sixth and fifth cranial nerves were preserved with affection of the eight and the seventh cranial nerves.

Radiological features alone are insufficient to make an accurate preoperative diagnosis. CT scan demonstrates a slightly hyper dense lytic lesion with enhancement after contrast infusion. MRI demonstrates both cystic and solid components usually hypo intense or iso intense on T1 and T2 with heterogeneous enhancement after gadolinium infusion. The differential diagnosis should include "brown tumor" of hyperparathyroidism, eosinophilic granuloma, chordoma, aneurysmal bone cyst, plasmacytoma and chondroma [9].

GCT's histopathology consists of spindle mononuclear stromal cells, which are the true neoplastic component, multinucleated giant cells and monocyte/ macro-phage family cells. The spindle stromal cells secrete the Receptor Activator of Nuclear Factor Kappa-B-Ligand (RANKL) affecting the immune system and control bone regeneration and remodel by binding RANK, a receptor expressed on the surface of the multinucleated giant cells [10]. This finding has led to therapeutic targeting as Denosumab, a fully human monoclonal antibody against RANKL recently approved by the Food and Drug Administration (FDA) and by the European Medicines Agency (EMA) for GCT [10] [11].

Surgical excision remains the treatment of choice but with recurrence rates up to $40 \%-60 \%$ correlated to the tumor size and extent of surgical resection [12]. Despite the improvements in surgical techniques, complete tumor removal without functional deficits remains challenging in skull base lesions, as seen in this case [13]. Therefore, considering both the possibility of incomplete resection and high recurrence rates, adjuvant therapy is considered necessary for local control.

Radiation used as a single modality or adjuvant therapy remains controversial because of low rates of local control, concerns about side effects and induction of malignant transformation [13]. However, radiation therapy techniques have strongly improved over the last decade, achieving dose escalation with high homogeneity/conformity indices and maximum adjacent tissue sparing. Several studies using modern radiotherapy techniques (IMRT, RapidArc and radiosurgery) for 
GCT reported a good local control rate with marked symptoms reliefs without severe toxicity, as well as incident of less than $1 \%$ of malignant transformation [12] [13] [14] [15]. The recommended dose is 45 - $60 \mathrm{~Gy}$ to achieve a long-term control of the tumor [3], in this case we calculated a total dose of $20.1 \mathrm{~Gy}$ delivered in three fractions of 6.7 Gy each equaling a biologically effective dose of approximate $44 \mathrm{~Gy}$. No acute or late radiation side effects were seen during the follow-up periods.

There is limited evidence regarding the use of chemotherapy and it is considered not active in GCTs [10]. Bisphosphonates agents have shown some activity in GCTs but are not currently approved due to lack of information and randomized studies [10] [11]. Denosumab results demonstrated long lasting responses with $96 \%$ of progression-free patients at a median follow up of 15 months and incredible response in the 8 patients with skull base GCTs [16]. Chawla et al., reported that denosumab was associated with a great tumour response and reduced the need for morbid surgery with only $1 \%$ of osteonecrosis of the jaw and 5\% of hypocalcaemia reported [17]. However, no long term data about the recurrence rate, functional outcome and long term toxicity exists so far and therefore we need to wait for the final analysis of the phase 2 study that has been published only in part at the moment.

Denosumab alone have shown to work by inhibiting the recruitment and the differentiation of giant cell component of the tumour, not directly to the stromal cells and tumour re-growth is expected after discontinuation of the drug. This strongly suggests the need for prolonged treatment or the used of combined therapy to enhance long term local control. Our case illustrates the used of combined therapy, SRS and denosumab after subtotal resection of the tumor, resulting in excellent tumour control after 48 months. Further investigation on the use of combined therapy for skull base GCTs is necessary to define adjuvant setting and treatment duration.

\section{References}

[1] Fletcher, C.D.M., Bridge, J.A., Hogendoom, P.C.W., Mertens, F., Eds. (2013) WHO Classification of Tumours of Soft Tissue and Bone. IARC Press, Lyon.

[2] Sasagawa, Y., Tachibana, O., Shiraga, S., Takata, H., Kinoshita, E., Nojima, T., et al. (2012) Secondary Malignant Giant Cell Tumor of the Clivus: Case Report. Clinical Neurology and Neurosurgery, 114, 786-788. https://doi.org/10.1016/j.clineuro.2011.12.041

[3] Zhao, J., Qian, T., Zhi, Z., Li, Q., Kang, L., Wang, J., et al. (2014) Giant Cell Tumor of the Clivus: A Case Report and Review of Literature. Oncology Letters, 8, 27822786. https://doi.org/10.3892/ol.2014.2528

[4] Inoue, A., Ohnishi, T., Kohno, S., Nishikawa, M., Nishida, N. and Ohue, S. (2016) Role of Denosumab in Endoscopic Endonasal Treatment for Juvenile Giant Cell Tumor: A Case Report and Review of Literature. World Neurosurgery, 91, 674.e1674.e6. https://doi.org/10.1016/j.wneu.2016.04.054

[5] Gupta, R., Mohindra, S., Mahore, A., Mathuriya, S.N. and Radotra, B.D. (2008) Giant Cell Tumor of the Clivus. British Journal of Neurosurgery, 22, 447-449. https://doi.org/10.1080/02688690701818943 
[6] Uslu, G.H., Canyilmaz, E., Yöney, A., Aydin, S., Sahbaz, A. and Sari, A. (2014) Giant Cell Tumor of the Occipital Bone: A Case Report and Review of the Literature. Oncology Letters, 8, 151-154. https://doi.org/10.3892/ol.2014.2086

[7] Wang, Y., Honda, K., Susuki, S. and Ishikawa, K. (2006) Giant Cell Tumor at the Lateral Skull Base. American Journal of Otolaryngology, 27, 64-67.

https://doi.org/10.1016/j.amjoto.2005.05.021

[8] Jada, A.S., Shrivastava, R., Mannan, A., Kobets, A. and Manolidis, S. (2015) Rare Presentation of Giant Cell Tumor in the Auditory Canal: Case Report and Review of the Literature. Journal of Neurological Surgery Reports, 76, e65-e71. https://doi.org/10.1055/s-0034-1396656

[9] Murphey, M.D., Nomikos, G.C., Flemming, D.J., Gannon, F.H., Temple, H.T. and Kransdorf, M.J. (2001) Imaging of Giant Cell Tumor and Giant Cell Reparative Granuloma of Bone: Radiologic-Pathologic Correlation. Radiogahics, 21, 12831309. https://doi.org/10.1148/radiographics.21.5.g01se251283

[10] Colia, V., Provenzano, S., Hindi, N., Casali, P.G. and Stacchiotti, S. (2016) Systemic Therapy for Selected Skull Base Sarcomas: Chondrosarcoma, Chordoma, Giant Cell Tumour and Solitary Fibrous Tumour/Hemangiopericytoma. Reports of Practical Oncology and Radiotherapy, 21, 361-369. https://doi.org/10.1016/j.rpor.2015.12.005

[11] Thomas, D., Henshaw, R., Skubitz, K., Chawla, S., Staddon, A., Blay, J.Y., et al. (2010) Denosumab in Patients with Giant-Cell Tumour of Bone: An Open-Label, Phase 2 Study. The Lancet Oncology, 11, 275-280. https://doi.org/10.1016/S1470-2045(10)70010-3

[12] Balke, M., Ahrens, H., Streitbuerger, A., Koehler, G., Winkerlmann, W., Gosheger, G., et al. (2009) Treatment Options for Recurrent Giant Cell Tumors of Bone. Journal of Cancer Research and Clinical Oncology, 135, 149-158. https://doi.org/10.1007/s00432-008-0427-x

[13] Roeder, F., Timke, C., Zwicker, F., Thieke, C., Bischof, M., Debus, J., et al. (2010) Intensity Modulated Radiotherapy (IMRT) in Benign Cell Tumors: A Single Institution Case Series and Short Review of the Literature. Radiation Oncology, 5, 18. https://doi.org/10.1186/1748-717X-5-18

[14] Kim, I.Y., Jung, S., Jung, T.Y., Moon, K.S., Jang, W.Y., Park, S.J., et al. (2012) Gamma Knife Radiosurgery for Giant Cell Tumor of the Petrous Bone. Clinical Neurology and Neurosurgery, 114, 185-189. https://doi.org/10.1016/j.clineuro.2011.10.007

[15] Saeed, E.F., Tunio, M. and Gabriela, S. (2014) Giant Cell Tumor Of Lumbar Spine Treated with Rapid Arc Intensity Modulated Arc Therapy: Case Report and Review of Literature. Journal of Cancer Research and Therapeutics, 5, 611-617. https://doi.org/10.4236/jct.2014.56070

[16] Rutkwoski, P., Ferrari, S., Grimer, R.J., Stalley, P.D., Dijkstra, S.P., Pienkowski, A., et al. (2015) Surgical Downstaging in a Open-Label Phase II Trial of Denosumab in Patients of Giant Cell Tumor of Bone. Annals of Surgical Oncology, 22, 2860-2868. https://doi.org/10.1245/s10434-015-4634-9

[17] Chawla, S., Henshaw, R., Seeger, L., Choy, E., Blay, J.Y., Ferrari, S., et al. (2013) Safety and Efficacy of Denosumab for Adults and Skeletally Mature Adolescents with Giant Cell Tumour of Bone: Interim Analysis of an Open-Label, ParallelGroup, Phase 2 Study. The Lancet Oncology, 14, 901-908. https://doi.org/10.1016/S1470-2045(13)70277-8 
Submit or recommend next manuscript to OALib Journal and we will provide best service for you:

- Publication frequency: Monthly

- 9 subject areas of science, technology and medicine

- Fair and rigorous peer-review system

- Fast publication process

- Article promotion in various social networking sites (LinkedIn, Facebook, Twitter, etc.)

- Maximum dissemination of your research work

Submit Your Paper Online: Click Here to Submit

Or Contact service@oalib.com 